\title{
NEW APPROACH TO IMPROVE TAXOL BIOSYNTHETIC
}

\author{
H. N. Badi ${ }^{1}$, V. Abdoosi ${ }^{2}$, N. Farzin ${ }^{3 *}$ \\ ${ }^{1}$ Cultivation \& Development Department of Medicinal Plants Research Centre, Institute of Medicinal \\ Plants, ACECR, Karaj, Iran \\ ${ }^{2}$ Departments of Horticulture, Science and Research Branch, Islamic Azad University Tehran, Iran \\ ${ }^{3}$ Department of Biotechnology, Medicinal Plant Research Center of Barijessence, Kashan, Iran
}

\begin{abstract}
Taxol (Generic name for paclitaxel) is a complicated diterpene compound that is initially isolated from yew plants. Taxol is one of the most exciting natural ingredients to treat various cancers, including breast cancer, ovarian carcinoma, melanoma, and lung cancer. Limited number of yew trees, low content of taxol in plant tissue, slow growing and killing the tree to bark harvesting are significant restrictions that have led to the supply and availability of this important substance faced with challenges. Many attempts to complete synthesis, semi-synthesis, finding new source e.g alternative spices, other plant, microorganisms and establishment of the cell suspension cultures have been carried out. Cell culture is an appropriate strategy for stable production by using a small part of the plant as explants. Elicitors such as methyl jasmonate family compounds are powerfull stimulator for production of taxol. Methyl jasmonate increases the amount of taxol by enhancing the expression levels of taxol biosynthesis enzymes such as Geranyl-geranyl pyrophosphate synthase (GGPPs) and taxadienesynthesis (TDS). New approach including genetic and metabolic engineering can be led to increasing the taxol production by the over-expression of genes controlling limiting steps or by suppressing the undesired taxanes by employing antisense technology. The yew-coding genes associated with the production of taxol have been cloned. However, genetic manipulation strategies are not yet complete. This paper reviews the various ways to improve Taxol production.
\end{abstract}

Key words: Taxol, Elicitors, Cell Suspension Culture, Genetic engineering, Endophytic fungi

\section{INTRODUCTION}

Taxanes, including paclitaxel, isolated initially from the bark of the Taxus brevifolia (Pacific yew), is known as remarkable toxic compound to treat various cancer cells by binding to their B-tubulin subunit and antagonizing their disassembly [1]. Despite increasing demand for Paclitaxel as chemotherapeutic drugs, its concentration in yew bark is low and extraction process is complicated and expensive [2]. Yield of Taxol is about 0.5 gram per 30 pounds of bark. Approximately 30,000 $\mathrm{kg}$ of Taxus biomass required to produce $1 \mathrm{~kg}$ of refined Taxol. Over-harvesting of yew bark has been led to serious damage on Taxus forest $[3,4]$. Various attempts have been employed for increasing accessibility and finding new sources of paclitaxel. Already complete synthesis of taxol has been achived but its procedure is very expensive and requires many

\footnotetext{
*Correspondence to: Narjes Farzin, Department of biotechnology, Medicinal plant Research Center of Barijessence, Kashan, Iran E-mail: farzin_biotech@yahoo.com,Tell: +989131622225
}

reactions. So it is not involved in the drug commercial production. Semi-synthesis of taxol is dependent on natural compounds such Bacatin III. The leaves and stems are more considerable as a renewable resource for precursors $[5,6]$.

Plant cell, tissues and organ culture make it possible the rapid and mass multiplication of plants and production of secondary metabolites in controlled conditions, independent of the environment. It is also possible to increase the production of compounds than the intact plant and produce new compounds. Taxol purification from cell culture is easier than its purification from plant because of less interfering compound [7]. In recent years, cell suspension cultures have been considered to study the biosynthesis of secondary metabolites produced metabolites. Medium, explant, physical conditions, the addition of precursors, living and non-living inducers, and selection of high-efficiency cells are the most important factors that increase the production of secondary metabolites $[8,9]$. 
Plant genetic engineering has a significant role in the identification and genetic manipulation of enzymes involved in the metabolic pathway for the biosynthesis of secondary metabolites. Identification of taxol production biochemical pathways, gene over-expression and gene silencing may be able to remove a vast amount of the problems associated with its production. It seems essential to inquiry on genes involved in the biosynthesis of taxol, cloning and genetic manipulation of plants for improving the yield Taxol $[10,11]$.

\section{Taxus and Biological Characteristics}

Taxus is a genus of yews, in the Taxaceae family. It is non-resinous, evergreen gymnosperm, Shade-friendly understory plants. Leaves are lanceolate, flat, $2-3 \mathrm{~cm}$ long and spirally arranged on the stem. They have shiny dark green upper surface and a little pale yellowish green lower surface. Yew flowers are bisexual. Male flowers are small, round, and yellow and female flowers are solitary.Yew trees are mostly dioecious, but occasional individuals can be variably monoecious, or change sex with time. Cone containing a single seed, partly surrounded by a soft, bright red berry-like structure called an aril, is open at the end. The arils are mature 69 months after pollination. All parts (especially leaves and seeds) contain taxine alkaloids that are lethal to humans and animals. The aril is the only non-poisonous part of the plant [12].

The genus Taxus includes 24 species and Over 400 cultivars distributed across the northern temperate and subtropical. All of the yews are very closely related to each other. Some botanists believed that all of them are derived from $T$. baccata. Yew cultivars by difference in growth form, habit, needle form and colour are recognized [13].

Yew trees can be propagated by Seed, Cutting, rootstock and In vitro propagation. Seeds are spread by birds and Squirrels. They have deep dormancy about 1.5-2.0 years [14]. Yew tree growth is relatively slow and may take 100 years or more to achieve appreciable size. Many populations are in serious decline. They are widely used in landscaping and ornamental horticulture. Yew wood is very springy and traditionally used to make bows, turnery, cabinetry, crutches and a pawn. Yew is one of the ancient unique tree species that survived from Tertiary geological. So it is important due to its Paleontology and longevity. All parts of all Taxus species, except arils, contain a unique class of diterpenoid alkaloids (Taxanes) with antimitotic effect.

\section{Paclitaxel (Taxol ®)}

BADI H. N. et al.

A large number of taxoids, highly oxygenated diterpenes, as well as lignans, flavonoids, steroids and sugar derivatives have been isolated from various Taxus species. Taxanes including Paclitaxel prevent the growth of cancer cells by abnormal spindle formation. Paclitaxel as a unique anticancer drug bind to microtubules and inhibits their depolymerization into tubulin. It leads to stopping DNA replication at the G2/M mitotic division and thereby causes the death of cells in proliferation $[1,15]$.

During the 1960s researches on the natural anticancer compound led to the discovery of Paclitaxel. This substance was extracted from the bark of the Pacific Yew (Taxus brevifolia) by Wall and Wani (1963). Its Structure was determined as a complex diterpene in 1971. The molecular formula for paclitaxel is C47H51NO14 with the molecular weight of $853.93 \mathrm{~g} / \mathrm{mole}$ (Figure 1). Paclitaxel is lipophilic white crystalline powder and insoluble in water. It showed anti-tumor activity in 1971 and prevented cell division by promoting disassembly of microtubules (Horowitz, 1979).

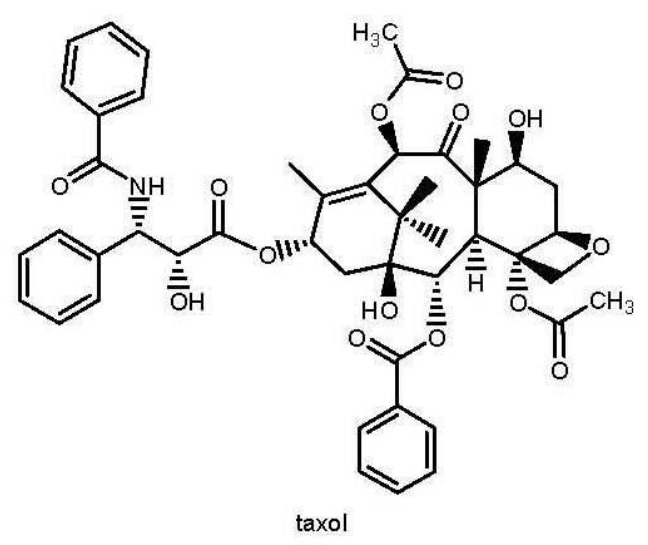

Figure 1. Paxiltaxel structural formula

Phase I clinical trials was started in 1983 [16] and Bristol-Myers Squibb was selected by National Cancer Institute (NCI) as commercial partner for developing this drug in 1991. Paclitaxel was marketed by this company as Taxol. It was approved by FDA for ovarian cancer (1992) and breast cancer (1994) [16]. Since then it has been approved for other forms of cancer such as non-small cell lung cancer, AIDS-related Kaposi's sarcoma, head and neck tumors, melanoma, urinary tract cancer, esophageal cancer, certain types of bone cancer and numerous clinical trials have been conducted for Taxol. Furthermore, it was also approved for advanced, methastatic and recurrent cancer $[1,3,7,15]$. 


\section{Identifition New Sources for taxol production}

There are too many bottlenecks for Taxol production. Supply is an important problem. There are not enough trees to treat patients. Most suitable trees for the extraction of taxol are more than one hanudered years old. Extraction of natural resources leads to its destruction. Taxol yield is very low, so to produce a gram of taxol it is required to bark three mature trees 100 years old [7]. Extract of bark is a complicated and expensive process. Other species of Taxus or other plants that not belonging to Taxus genus, chemical synthesis, semi-synthesis in the laboratory from precursors in needles, fungal on yews (endophytes) and Tissue and cell cultures have been surveyed as new sources for taxol production.

\section{Alternative species}

Taxol was isolated initially from $T$. brevifolia, the Pacific yew. Some researchers found that T. baccata (European Yew), T. caspidata and hybrids species such as $T$. $x$ media Hicksii produce Taxol precursors [5, 7]. These precursor are used for chemical synthesis of Taxol and can be converted to an analog of taxol in the laboratory [17].

\section{Other plants}

Hoffman and et al (1998) reported that hazel could be as a taxol-producing species [18] and it has been confirmed by recent studies [19, 20]. Although the amount of Taxol in every gram of branches and leaves of hazel is about 5 micrograms, but hazel has faster growing and wide distribution[21]. Hazel cell suspension culture has been operated to Taxol, 10deacetyltaxol and 10-deacetylbaccatin II production and elicitors were used to enhance productivity. Amount of taxanes has been increased through elicitation with methyljasmonate or methyljasmonate plus chitosan [19]. Phenylalanine (Phe) has shown positive effect on Taxol production by suspension-cultured hazel cells and its cytotoxic effects. It is interesting its cytotoxic activity was more standard Taxol [22]. Cell culture of hazel is eaiser and faster than yew and in future it can be a more relibele approach for Taxol production.

3-hydroxy-3-methyl-glutaryl-CoA reductase (HMGR), functional gene encoding in Taxol biosynthetic pathway, has been characterized in several plant including hazel (Yechun et al. 2007). Recently two key genes of the MEP pathway including IPI and GGPP have been cloned and characterized in hazel, which are precursors for Taxol [20, 23].

\section{Chemical synthesis}

Until 1994, chemical synthesis was a formidable challenge. Nowadays, several ways have been known to synthesize Taxol but cost per patient still is expensive. It is required 19 steps from the universal diterpenoid geranylgeranyl diphosphate (GGPP). Hence it is not involved in the commercial production $[24,25]$. A new method for the semisynthesis of Taxol from baccatin III has been attained via a dioxo-oxathiazolidine intermediate [26].

The paclitaxel molecule is composed of tetracyclic core ring: ring A (a cyclohexene), ring $\mathrm{B}$ (a cyclooctane), ring $\mathrm{C}$ (a cyclohexane) and ring $\mathrm{D}$ (an oxetane) with an amide tail. the first step is cyclization of GGPP by taxadienesynthase (TS) and conversion into taxa-4 (5), 11-diene that called taxadiene [27]. Taxadiene is hydroxylated by Taxadiene $5 \alpha$ hydroxulase to Taxa-4 (20), 11(12) diene-5 $\alpha$ ol. Hydroxylase enzyme that catalyzes this reaction is a cytochrome P450 [28]. The third step in the biosynthesis of Taxol is acetylation and formation of Oxetane ring by Taxa-4 (20), 11(12)-diene-5 $\alpha$-ol O-acetyltransferase (TAT). Synthesis of 10-deacetylbaccatinU catalized by Taxan 2 $\alpha$-o-debenzoyltransferase (TBT) and intermidate substrate converted to baccatin III by 10-deacetylbaccatinU 10-Oacetyltransferase (DBAT) (Figure 2) [29].

\section{Semi-synthetic Taxol}

It was found a semi-synthetic method for developing Taxol production from a molecule in needles of $T$. baccata. Leaves and twigs are a source of 10-deacetylbaccatin III (10-DAB), although yield much lower but they are more renewable resource $[5,30]$. Docetaxel [Taxotere] is partially-synthetic derivative of Taxol and results from the modification of paclitaxel's side chain. It acts to kill cancer cells in the same way as Paclitaxel and has potent cytotoxic activity. It is practical and useful in the treatment of prostate cancer, breast, ovarian and lung cancer [5].

Semi-synthesis of taxol is dependent on natural compounds such as Bacatin III. Investigations for isolation and extraction Taxol or its precursors from leaves and stems of other Taxus species, including T. baccata and $T$. caspidata and hybrids species (e.g. T. x media Hicksii) has been done [5, 7]. This method seems to be suitable for the production, but purification and isolation of the natural precursor for the synthesis of Taxol, due to the present waxes, chlorophyll, phenolic compounds, lipids and other interfering plant compounds is very complicated $[5,6]$. 


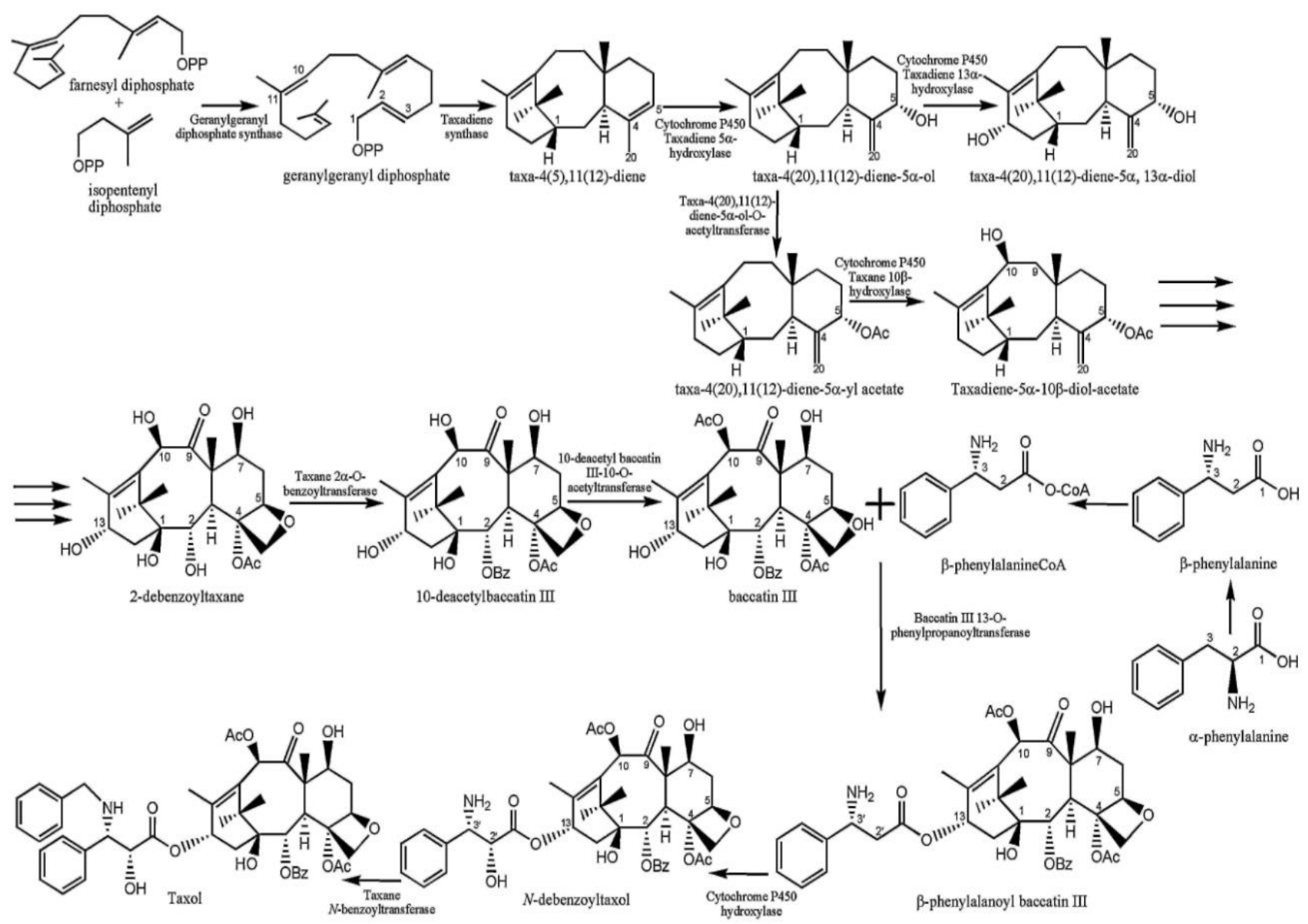

Figure 2. Taxol biosynethetic pathway [67]

\section{Tissue and cell culture}

Yew reproduction by seed are difficult because of troublesome collection and deep (about 1.52.0 years) dormancy $[14,31]$. Embryo culture could be used to overcome dormancy [14, 32].Tissue culture and rapid multiplication could be a way to overcome the problems to preserve genetic resources and reforestation. Stem cutting and in vitro multiple shoot could increase the number of available trees [33]. Zygotic embryo, bud and young are appropriate explants for micropropagation [34, 35]. Different media including MS, B5, and WPM have been suggested [9]. Casein, ascorbic acid and polyvinylpyrrolidone have been helpful [36]. Chee (1994) obtained in vitro yew seedlings from embryos $T$. brevifolia [32]. Plant regeneration was achieved from somatic embryogenesis [37]. Mass propagation of taxus was developed to produce more Taxol [38].

With respect to limtation of yew natural stock, the environmental impact on taxol and its high required purity, taxol production by plant cell suspension culture is a considerable way for stable and commercial procuction [7]. The first report on callus culture from gametophytes of T. baccata was presented in 1974 . Then the first abstract of taxol production in cell suspension culture calluses of T. brevifolia was published in 1983 [39]. Taxol production from callus culture by $0.2 \%$ yelid of the dry weight of $T$. cuspidate cultures was performed in 1992 [40]. Then Taxol $(15.33 \mathrm{mg} / \mathrm{l})$ was produced by 42-day cultures of $T$. chinensis [41]. Taxol was detected and evaluated in callus cultures by Wickremesinhe ERM (1993) [42].

Explants, Genotype, basal media, Phytohormones, organic supplements and additives are most important factors that have effect on callus induction. Cotyledons, hypocotyls, roots from young seedlings, young as well as mature stems, gametophytes, and needles have been used for callus induction. Young tissue from juvenile plant is more responsive to callus initiation than mature plant parts or young tissue from adult trees. Best basal media for initiation and maintenance of callus of Taxus are B5, MS, SH, WPM [9, 40, 43]. Casein hydrolysate, mannitol, polyninylpyrrolidone, ascorbic acid, amino acids and activated charcoal acan be stimulated callus growth and proliferation [9].

It is necessary stable, growing callus to Taxol production. Studies on taxol production 
BADI H. N. et al.

through tissue culture has shown that stem explants compared with leaf explants produce more callus as well as higher taxol content. Therefore stem are more appropriate for tissue culture to produce Taxol [44].

Plant cells Suspensions can be Impressive to produce secondary metabolites and recombinant proteins under controlled conditions in industrial scale. Cell suspension culture is more effective than callus for production of Taxanes. It was found to be secreted into the medium thus facilitating collection .Cell suspensions are initiated by inoculating friable calli into liquid medium and consist of single or small cell aggregates. These fast growing systems can be used for large scale culture of plant cells to obtain valuable products. Various strategies are being employed in continuing efforts to increase productivity [7, 45]. Cell suspensions suffer from low yeild of production of secondary metabolites and somaclonal variation. This pronlems can be reduced by careful selection of favorite calli, optimal growth conditions, medium and adding some elicitors [45]. Somaclonal variation can be positive or negative [46]; it is possible to choose desirable callus with high Taxol content.

Selection of high yielding cell lines, optimization of culture conditions, culture media components such as Sugar, phosphate, nitrate and plant growth regulators, carbohydrate source, explant, physical conditions, immobilization, phytohormones, elicitors, addition of precursors, adsorbants or additives, nutrient media and employment of a two-stage culture system are important factors can play a significant role to increase the growth and high accumulation of secondary metabolites [39, 45].

The content of Taxanes is significantly affected by basal media. Kajani and et al (2012) were observed effect of five commonly basal medium (B5, MS, SH, DKW and WPM) on production and secretion of taxanes from suspension cell culture of $T$. baccata $\mathrm{L}$. They observed best media for producing Baccatin III and10-deacetyl baccatin III was DKW basal media but Maximum yield of Taxol achieved by using WPM basal media [47]. A slight amount cephalomanine as taxane, was detected in embtryo callus cultyre of T. baccata [8].

Culture conditions such as light, temperature, $\mathrm{pH}$ and oxygen concentration are impact on secondary metabolites. Dark conditions are favorable for the growth of cells and Taxol production [48, 49]. Cell growth enhanced by fructose treatment and suppressed by glucose [48].

Bioreactors is final and major phase to industrial scale-up and commercial production [50, 51]. Cell suspension cultures of T. baccata and $T$. wallichiana were achieved in a $20-\mathrm{L}$ airlift bioreactor. Highest total content of Taxol and baccatin III was reached up to $21.04 \mathrm{mg} / \mathrm{L}$ and $25.67 \mathrm{mg} / \mathrm{L}$, respectively by $T$. wallichiana culture [51]. Cell culture of $\mathrm{T}$. cuspidata (Japanese yew) from callus derived from immature embryos was carried out for Taxol production in a balloon-type bubble bioreactor in 20-1 capacity. The highest yields of taxol $(3 \mathrm{mg} / \mathrm{l})$ and total taxanes $(74 \mathrm{mg} / \mathrm{l})$ were achieved after 27 days of culture [52].

\section{Elicitors}

Some additives such as vanadyl sulfate (VS), silver nitrate and cobalt chloride are involved in Taxus cell growth and induce high biomass production. Also methyl jasmonate (MJ), salicylic acid (SA) and fungal elicitor (FE) are used to increase Taxol yeild. Taxol production in cell suspensionculture of T.baccata L. was significantly enhanced by both abiotic and biotic elicitors. MJ induces the activity of geranyl geranyl diphosphate synthase. MJ as well as silver nitrate and ammonium citrate act on the path between baccatin III and Taxol. SA acts on the path before 10-deastyl baccatin III. MJ significantly activates both taxol and baccatin III production; clearly it increases the expression of the txs and bapt genes. Vanadyl sulfate only enhances bapt gene expression, so it is caused only high taxol production. So, Taxol and baccatin III levels increase 4-and 3.6-fold, over the controls in the presence MJ but Vanadyl sulphate only enhance 4-fold taxol production [53]. Khosroushahi (2006) observed that Taxol remarkably is increased by use of these elicitors more than 16-fold as compared with untreated B5 media [45].

Coronatine (Cor) is a toxin produced by Pseudomonas syringae. This substance has potential to act as a plant growth regulator and elicitor. Add Coronatine in cell suspension cultures of Taxus at the beginning of the second phase, has significantly effect on the amount of taxol. Coronatine is more effective than MJ [54]. Taxol production in suspension cultures have been elicited by fungal endophytes. Co-culturing of suspension cultures of $T$. chinensis and T. cuspidata with Fusarium mairei increasd Taxol production by 38-fold and two-fold, respictively [55].

\section{Genetic engineering}

In recent years, all of encoding genes associated taxol biosynthetic pathway have 
BADI H. N. et al.

been identified and cloned. Complete understanding biochemical pathway and how to regulate by enzymes is the first step to manipulation to high and commercially sustainable production. It is possible by the gene overexpression of controlling limiting steps or by suppressing the undesired taxanes by employing antisense technology.

Key enzymes involved in the Taxol biosynthetic pathway isolated and characterized, which is important and new option for high Taxol production. Key genes in taxol biosynthesis are $t s$ : encoding taxadiene synthase, involved in formation of the taxane skeleton, dbat: encoding 10-deacetylbaccatin III-10-O-acetyltransferase, using 10-DAB and acetyl CoA as substrates (involved in baccatin III formation), bapt: encoding C-13 phenylpropanoyl side chain-CoA acyltransferase (involved in phenylpropanoyl side chain formation at $\mathrm{C} 13$ ).

In yew trees, taxol biosynthesis involves 19 enzymatic steps [27, 56]. According to numerous studies on the metabolism of other terpenoids has been identified geranyl geranyl diphosphate (GGPP), which is main and general the precursor of taxol biosynthesis. The first step of taxol biosynthesis is the cyclization of GGPP by taxadiene synthase (TS), a plastidic enzyme, to the taxa-(4,5),(11,12)-diene, polihydroxylated intermediate. Conversion of GGPP to the Taxa-4 (20), 11 (12) diene is wrong pathway [27]. Taxadiene synthase is a monomeric protein with a molecular mass of $79 \mathrm{kDa}$. This enzyme has an optimal activity at $\mathrm{pH}=8 / 5$ and for optimal activity is required a divalent metal ion as a cofactor, that is $\mathrm{Mg}^{+2}$ much more efficient than $\mathrm{Mn}^{+2}$ [57]. Function of taxadiene synthase can not be easily proved in intact stem tissues of Taxus. Therefore T. canadensis cell suspension cultures have been used and enzyme was identified and isolated. It was found that this enzyme has the same acion with taxadiene synthase derived from stem of T. brevifolia. Analysis of enzyme activity during accumulation of taxol in cell culture showed that activity taxadiene synthase before taxol accumulation increases to reach the stationary phase [58].

Gene expression analysis has been implied that key genes involved in Taxol production: txs, dbat and bapt is variably induced by the presence of the elicitors (Onrubia M, 2013). Analysis of gene expression has been exhibited that in response to methyl jasmonate, gene expression levels increase up to 24 times at 12 hours after elicitation [59].

Transformation of $T$. chinensis suspension cells by Agrobacterium tumefaciens strain LBA4404 was lead to overexpression of $d b a t$ gene and improve taxol yield in cells of $T$. chinensis (P. Zhang, 2011). 10deacetylbaccatin III-10-O-acetyl transferase (DBAT) gene was isolated from the plant $T$. chinensis and transformed into the cells of mushroom Flammulina velutipes by polyethylene glycol-mediated protoplast transformation. DBAT gene was expressed in F. velutipes, and DBAT is able to convert substrate into baccatin III [60].

\section{Endophytic fungi}

Endophytes are resident micoorganisms in a plant without causing disease to the host, that are promising sources in producing some of the natural and valuable compound such as Taxol, Camptothecin and Podophyllotoxin. Endophytic fungi are fungi that inhabit asymptomatically within the tissues of higher plants. [61, 62]. The fungal endophyte stimulates its host to produce a fungicide to which it is resistant, perhaps to remove rivals [63]. Taxol is a fungicide, and the endophyte is resistant to Taxol. Taxol content in Taxus trees is variable from tree to tree for not clear reasons [55].

First report about Taxol producing fungus (Taxomyces andreanae) was a attractive revolution in Taxol production [64]. Now it is evident that Taxol can be synthesized by at least 18 different fungal genera [55].

Taxol content in plant have a good correlation with Taxol-producing fungal endophyte. Fungal endophyte induces transcription of ratelimiting genes in the plant Taxol biosynthetic pathway. therefore fungicides by reduction of fungal endophyte lead to decrease Taxol content and transcript and/or protein levels corresponding to two critical genes required for plant Taxol biosynthesis [63].

A Taxol-producing endophyte isolated from $T$. $x$ media and it was identified as Paraconiothyrium SSM001. It could produce Taxol in intact plant and in vitro culture. Salicylic acid induced Taxol production from Paraconiothyrium SSM001, moderately. But its Co-culture with Alternaria (a bark fungus) increased Taxol production by $\sim$ three-fold. Morever Co-culture SSM001 with Alternaria and Phomopsis caused eight-fold increase in Taxol production [65].

Pestalotiopsis versicolor was isolation from the healthy leaves and bark of T.cuspidate (Japanese Yew tree) and idinetifed as Taxol-producing endophyte. PCR analysis have been confirmed the presence of $t s$ gene, a key gene in Taxol biosynthesis pathway (Kumaran RS, 2010). Diaporthe phaseolorum -a producing baccatin III endophyte was isolated from $T$. wallichiana var. 
mairei. The maximum content of baccatin III in culture was $0.219 \mathrm{mg} / \mathrm{l}$. Hence, it could be
BADI H. N. et al. promising source of baccatin III and paclitaxel [66].

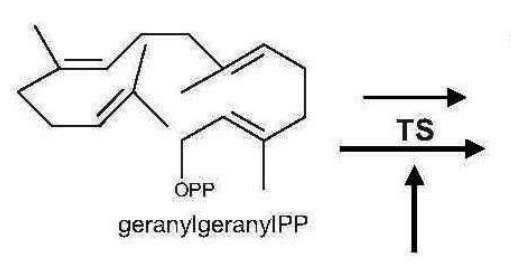

MJ

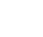

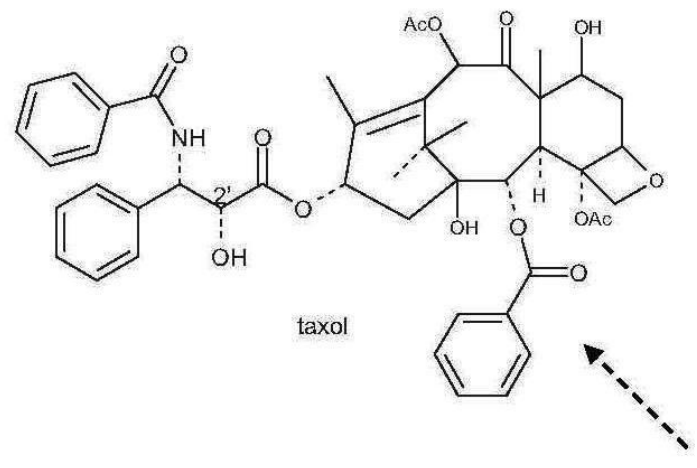

(C)

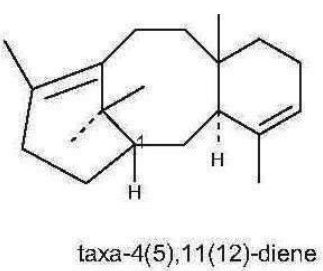

taxa-4(5),11(12)-diene

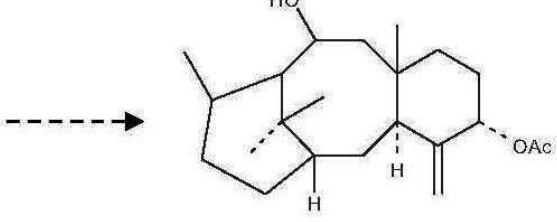

$\operatorname{taxa-4}(20), 11(12)$-dien-5 $\alpha$-10 $\beta$-diol-acetate

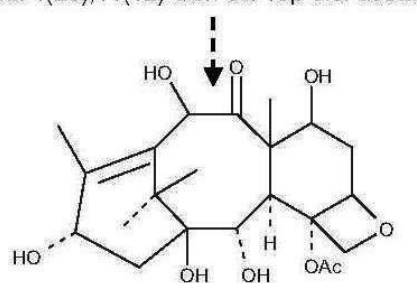

Hypotetical polihydroxylated intermediate<smiles>N[C@@H](Cc1ccccc1)C(=O)O</smiles>

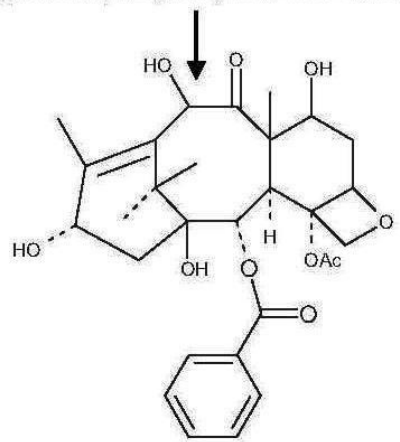

10-deacetylbaccatin III<smiles>C=C(CC(C)c1ccccc1)OCCO</smiles>

$\beta$-phenylalanoylCoA

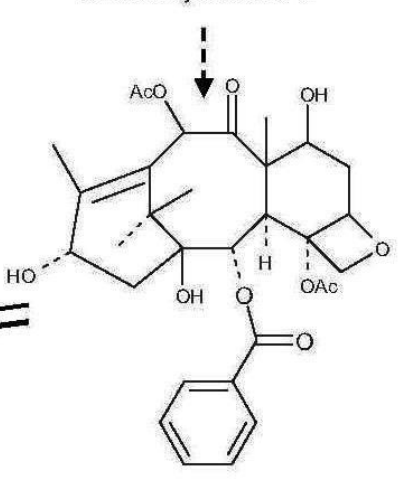

MJ VS

baccatin III

3'-N-debenzoyl-2'-deoxytaxol

Figure 3. The positive action of the elicitors MeJ and Vs on Taxol biosyentesis [53]

\section{CONCLUSION}

Taxol is one of the most important anticancer drugs, specifically for women. Many populations of Taxus are in serious decline. Moreover, Extraction from their natural sources is difficult and too expensive and complex to produce by chemical synthesis.

These empirical methods have not been able to for growing world demand for Taxanes.

Biotechnology is able to increase the efficacy medicinal plants to produce pharmaceutical drugs. Although the production of secondary metabolites by cell suspension cultures and tissues has been investigated in a wide range of medicinal plants, but at present these method is employed only for high value compounds such as taxol, anticancer drugs. Taxol production in suspension cultures has been improved by optimizing culture conditions, assaying several basic media, plant growth regulators, sugar supplements, elicitors, etc, and cultures have been scaled up to a bioreactor level for largescale production [50]. The use of biological and non-biological elicitors, identification and genetic manipulation of enzymes involved in 
BADI H. N. et al.

the metabolic pathway of taxol biosynthesis and genetic manipulation of plants and fungi, more efficient and more economical to produce Taxol provides.

With a full understanding of the taxol biosynthetic pathway and its involved genes, it may be possible to bioengineer Taxus for high and commercially sustainable production of Taxanes. The discovery could lead to new insight into how the Taxol biosynthetic pathway is regulated, with genetic and metabolic engineering techniques, differential genetic expression, transcription factors and key genes leading to higher Taxol yields. It is possible to increase the production of paclitaxel and other desirable taxanes either by the over-expression of genes controlling limiting steps or by suppressing the undesired taxanes by employing antisense technology. Recently, Metabolic engineering in microbes has attracted to produce large amounts of Taxol [60].

\section{REFERENCES}

1. Slichenmyer, W. and D. Von-Hoff. New Natural Products in Cancer Chemotherapy. J Clin Pharmacol 30(9): 770-788,1990.

2. Ghassempour, A., M. Noruzi, M. Zandehzaban, Z. Talebpour, A.Y. Khosroshahi, et al., Purification of Paclitaxel Isolated from Taxus Baccata L. Cell Culture by Microwave-Assisted Extraction and Two-Dimensional Liquid Chromatography. Journal of Liquid Chromatography \& Related Technologies 31(3): 382-394,2008.

3. Joyce, C., Taxol: Search for a Cancer Drug. BioScience 43(3): 133-136,1993.

4. Hoffman, A., C.C.J. Voelker and A.T. Franzen. Transfer of Taxol from Yew Tree Cuttings into a Culture Medium over Time. US 5620875 A. 1995.

5. Commercon, A., J. Bouzar, E. Didier and F. Lavelle. Paclitaxol Semisynthesis and Antimiotic Activity of Docetaxel and SideChain Analogs. ACS. Symp. Ser 583: 233246,1995.

6. Holton, R., R. Biediges and P. Boatman. Semisynthesis of Taxol and Taxotere. In: Suffiiness M (Ed), Taxol: Science and Applications, CRC press.1995.

7. Khosroshahi, A.Y., B.H. Khaniani and H. Naghdibadi. Review on Taxol as the Most Important Anti-Cancer Natural Drug. Journal of Medicinal Plants 5(18): 91,2006 .

8. Mihaljevic, S.A., I. Bjedov, M. Kova, D.L. Levanic and S. Jelaska. Effect of Explant Source and Growth Regulators on in Vitro Callus Growth of Taxus Baccata L.
Washingtonii. Food Technol. Biotechnol 40(4): 299-303,2002.

9. Khosroushahi, A.Y., M. Valizadeh, A. Ghasempour, M. Khosrowshahli and $\mathrm{H}$. Naghdibadi. Effect of Culture Media, Explants and Growth Regulators on Callus Induction and Taxol Production in Taxus Baccata L. Iranian Journal of Agriculture science 37(1): 76-69,2006.

10.Walker, K.D., K. Klettke, T. Akiyama and R. Croteau. Cloning, Heterologous Expression, and Characterization of a Phenylalanine Aminomutase Involved in Taxol Biosynthesis. J Biol Chem 279: 53947-53954,2004.

11.Walker, K. and R. Croteau. Molecular Cloning of a 10-Deacetylbaccatin Iii-10-OAcetyl Transferase Cdna from Taxus and Functional Expression in Escherichia Coli. Proc Natl Acad Sci USA 97: 583-587,2000.

12.Yazdani, D., S. S, R. Sh and P.H. M. Review on Yew Tree (Taxus Spp.). Journal of Medicinal Plants 4(15): 1-8,2005.

13.Itokawa, H. and K.H. Lee. Taxus the Genus Taxus. London and new york., Taylor and Francis.2002.

14.Nasr, S.M.H., S. Modanloo, H. Jalilvand and A.J. Mofidabadi. Seed Dormancy Breakage of Recalcitrant Yew Species (Taxus Baccata L.) Using Embryo Culture. Journal of Biological Sciences 7: 781$785,2007$.

15.Hortuwitz, S., Mechanism of Action of Taxol. Treands. Pharmacol. Sci 13: 134136,1992.

16.Mcguire, W., E. Rowinsky, N. Rosenshein, F. Grumbine, D. Ettinger, et al., Taxol: A Unique Antieoplastic Agent Significant Activity in Advanced Ovarion Epithelial Neoplasmas. Ann. Intern. Med 111: 273$279,1989$.

17.Vidensek, N., P. Lim, A. Campell and C. Carlos. Taxol Content in Bark, Wood, Root, Leaf, Twing and Seeding from Several Taxus Species. J Nat Prod 53: 1609-1610,1990.

18.Hoffman, A., K. W, J. Worapong, G. Strobel, D. Griffin, et al., Bioprospecting for Taxol Angiosperm Plant Extracts. Spectroscopy 13: 22 - 32,1998.

19.Bestoso, F., L. Ottaggio, A. Armirtti, A. Balbi, G. Damonte, et al., In Vitro Cell Cultures Obtained from Different Explants of Corylus Avellana Produce Taxol and Taxanes. BMC Biotechnol 6(45),2006.

20. Yechun, W., G. Binhui and T. Kexuan. Molecular Cloning, Expression Profiling and Functional Analyses of a Cdna Encoding Isopentenyl Diphosphate 
Isomerase from Hazel (Corylus Avellana L. Gasaway). Molecular Biol. Reports,2010.

21.Qaderi, A., M. Omidi, A. Etminan, A. Oladzad, C. Ebrahimi, et al., Hazel (Corylus Avellana L.) as a New Source of Taxol and Taxanes. Journal of Medicinal Plants 11(41): 66-77,2001.

22.Bemani, E., F. Ghanati, A. Rezaei and M. Jamshidi. Effect of Phenylalanine on Taxol Production and Antioxidant Activity of Extracts of Suspension-Cultured Hazel (Corylus Avellana L.) Cells. J Nat Med. 67(3): 446-445,2013.

23.Wang, Y., Z. Miao and K. Tang. Molecular Cloning and Functional Expression Analysis of a New Gene Encoding Geranylgeranyl Diphosphate Synthase from Hazel (Corylus Avellana L. Gasaway). Molecular Biol. Reports 37(7): 3439$3444,2010$.

24.Croteau, R., R.E.B. Ketchum, R.K. Robert M. Long and M.R. Wildung. Taxol Biosynthesis and Molecular Genetics. Phytochem Rev 5(1): 75-97,2006.

25.Hezari, M. and R. Croteau. Taxol Biosynthesis: An Update. Planta. Medica 63: 291-295,1997.

26.Baloglu, E. and D.T. Kingston. A New Semisynthesis of Paclitaxel from Baccatin Iii. J.Nat. Prod 62: 1448-1472,1999.

27.Koepp, A., M. Hezari, J. Zajicek, B.S. Vogel, R. Lafever, et al., Cyclization of Geranylgeranyl Diphsphate to Taxa4(5)11(12)-Diene Is the Commited Step of Taxol Biosynthesis in Pacific Yew Biol. Chem 270: 8686-8690,1995.

28.Mihaliak, C., F. Karp and R. Croteau. Cytochrome P-450 Terpene Hydroxylases in Lea Pj. Ed. Methods Plant Biochem. Enzymes of Secondary Metabolism. London, Academic press.1993.

29. Vazquez, A. and R. Williams. Studies on the Biosynthesis of Taxol, Synthesis of Taxa-4 (20), 11 (12)-Diene-2 $\alpha, 5 \alpha$-Diol. $J$. AM. Chem. Soc 65: 7865-7869,2000.

30.Jennewin, S. and R. Croteau. Taxol Biosynthesis: Taxan 13 $\alpha$ - Hydroxylase Is a Cytochrom P450- Dependent Mono Oxygenase. Appl. Microbial. Biotechnol. 57: 13-19,2001.

31.Page, L. and M.T. Degivry. Physiologies, Acid Abscisic in Dormancy of Embryo of Taxus Baccata. L.C.R., Paris 271: 482484,1970.

32.Chee, P.P., In Vitro Culture of Zygotic Embryos of Taxus Species. Hort Science 29: $695-697,1994$.

33.Chee, P.P., Organogenesis in Taxus Brevifolia Tissue Cultures. Plant Cell Reports 14(9): 560-565,1995.
34.Chang, S.H., C.K. Ho and Z.Z. Chen. Micropropagation of Taxus Mairei from Mature Trees. Plant Cell Reports 20: 496$502,2001$.

35.Abbasin, Z., S. Zamani, S. Movahedi, G. Khaksar and B.E.S. Tabatabaei. In Vitro Micropropagation of Yew (Taxus Baccata) and Production of Plantlets. Biotechnology 9(1): 48-54,2010.

36.36. Chang, S. and J. Yang. Enhancement of Plant Formation from Embryo Cultures of Taxus Mairei Using Suitable Culture Medium and Pvp. . Bot. Bull. Acad 37: 3540,1996.

37. Chee, P.P., Plant Regeneration from Somatic Embryos of Taxus Brevifolia. Plant Cell Reports 16(3-4): 184-187,1996.

38.Majada, J.P., M.I. Sierra and R.S.-. Tames. One Step More Towards Taxane Production through Enhanced Taxus Propagation. Plant Cell Reports 19: 825 - 830,2000.

39.Zhong, J.-J., Plant Cell Culture for Production of Paclitaxel and Other Taxanes. Journal of Biosience and Bioengineering 94(6): 591-599,2002.

40.Fett-Neto, A.G., J.M. Stewart, S.A. Nicholson, J.J. Pennington and F. DiCosmo. Improved Taxol Yield by Aromatic Carboxylic Acid and Amino Acid Feeding to Cell Cultures of T. Cuspidata. Biotechnology Bioengineering 44: 967971,1994.

41.Luo, J., L. Liu and C.D. Wu. Enhancement of Paclitaxel Production by Abscisic Acid in Cell Suspension Cultures of Taxus Chinensis Biotechnol Lett 23: 13451348,2001.

42.Wickremesinhe, E.R.M. and R.N. Arteca. Taxus Callus Cultures: Initiation, Growth Optimization, Characterization and Taxol Production. Plant Cell, Tissue and Organ Culture 35(2): 181-193,1993.

43.Ketchum, R., D.M. Gibson and L.G. Gallo. Media Optimization for Aximum Biomass Production in Cell Culture of Pacific Yew. Plant Cell, Tissue and Organ Culture 42: 185-193,1995.

44.Ghafoori, R., F. Bernard, S. Abolmaali and A. Mousavi. Improved Effect of Glutathione on the Induction and Growth of Taxus Baccata L. Callus. Annals of Biological Research 3(4): 1726-1730,2012.

45.Khosroushahi, A.Y., M. Valizadeh, A. Ghasempour, M. Khosrowshahli, H. Naghdibadi, et al., Improved Taxol Production by Combination of Inducing Factors in Suspension Cell Culture of Taxus Baccata. Cell Biology International 30: 262-269,2006. 
BADI H. N. et al.

46.Larkin, P.J. and W.R.S. Wr. Somaclonal Variation-a Novel Source of Variability from Cell Cultures for Plant Improvement. Theor Appl Genet 60: 197-214,1981.

47.Abbasi-Kajani, A., S. Moghim and M.R. Mofid. Optimization of the Basal Medium for Improving Production and Secretion of Taxanes from Suspension Cell Culture of Taxus Baccata L DARU Journal of Pharmaceutical Sciences 20(54): 1-6,2012.

48.Hirasuna, T., L. Pestchanker, V. Srinivasan and M. Shuler. Taxol Production in Suspension Cultures of Taxus Baccata. Plant Cell Tiss Org Cult 44: 95-102,1996.

49. Chen, Y., W. Zhu, Y. Wu and Q. Hu. Effects of Culture Conditions on Callus Growth and Taxol Formation of Taxus Yunnanensis Cheng Et L.K.Fu. China journal of Chinese materia medica 25(5): 269-272,2000.

50.Shuler, M., Bioreactor Engineering as an Enabling Technology to Tap Biodiversity. The Case of Taxol. Ann N Y Acad Sci. 745: 455-461,1994.

51.Navia-Osorio, A., H. Garden, R.M. Cusidó, J. Palazón, A.W. Alfermann, et al., Taxol and Baccatin Iii Production in Suspension Cultures of Taxus Baccata and Taxus Wallichianain an Airlift Bioreactor. J. Plant Physiol 159: 97-102,2002.

52.52. Son, S.H., S.M. Choi, Y.H. Lee, K.B. Choi, S.R. Yun, et al., Large-Scale Growth and Taxane Production in Cell Cultures of Taxus Cuspidata (Japanese Yew) Using a Novel Bioreactor. Plant Cell Rep 19(6): 628-633,2000.

53. Onrubiab, M., E. Moyanob, M. Bonfilla, O. Expositoa, J. Palazona, et al., An Approach to the Molecular Mechanism of Methyl Jasmonate and Vanadyl Sulphate Elicitation in Taxus Baccata Cell Cultures: The Role of Txs and Bapt Gene Expression. Biochemical Engineering Journal 53: 104111,2010.

54. Onrubia, M., E. Moyano, M. Bonfill, R. Cusidó, A. Goossens, et al., Coronatine, a More Powerful Elicitor for Inducing Taxane Biosynthesis in Taxus Media Cell Cultures Than Methyl Jasmonate. J Plant Physiol 170(2): 211-219,2013.

55.Li, Y.C., W. Tao and L. Chen. Paclitaxel Production Using Co-Culture of Taxus Suspension Cells and Paclitaxel-Producing Endophytic Fungi in a Co-Bioreactor. Appl Microbiol Biotechnol 83(2): 233-239,2009.

56. Ghershenzon, J. and R. Croteau. Terpenoid Biosynthesis: The Basic Pathway and Formation of Monoterpenes, Sesquiterpenes, and Diterpenes. In: Moore
Ts (Ed). Lipid Metabolism in Plants, CRC press, Boca Raton, FL.1993.

57.Hezata, M., L. Ng and R. Croteau. Purification and Characterization of Taxa-4 (5), 11 (12)-Diene Synthase from Pacific Yew (Taxus Brevifolia) That Catalyzes the First Committed Step of Taxol Biosynthesis. Arch. Biochem. Biophys 322: 437-444,1995.

58.Hezari, M., R. Ketchum, D. Gibson and R. Croteau. Taxol Production and Taxadiene Synthase Activity in Taxus Canadensis Cell Suspension Cultures. Arch Biochem Biophys 337(2): 185-190,1997.

59.Majidi, M., M. Farsi, A. Bahrami, J. Behravan and S. Marashi. Cloning, Gene Expression Analysis, and Phylogenic Relationship of Dbat Gene from Iranian Endemic Yew (Taxus Baccata L.). Journal of Medicinal Plants 12(48): 91-103,2013.

60.Han, F., L. Kang, X. Zeng, Z. Ye, L. Guo, et al., Bioproduction of Baccatin Iii, an Advanced Precursor of Paclitaxol, with Transgenic Flammulina Velutipes Expressing the 10-Deacetylbaccatin Iii-10O-Acetyl Transferase Gene. J Sci Food Agric 94(12): 2376-2383,2014.

61.Strobel, G. and B. Daisy. Bioprospecting for Microbial Endophytes and Their Natural Products. Microbiol Mol Biol Rev 67(4): 491-502,2003.

62.Aly, A., A. Debbab and P. Proksch. Fungal Endophytes - Secret Producers of Bioactive Plant Metabolites. Pharmazie 68(7): 499505,2013.

63.Soliman, S., C. Trobacher, R. Tsao, J. Greenwood and M. Raizada. A Fungal Endophyte Induces Transcription of Genes Encoding a Redundant Fungicide Pathway in Its Host Plant. BMC Plant Biol,2013

64. Stierle, A., G. Strobel and D. Stierle. Taxol and Taxane Production by Taxomyces Andreanae, an Endophytic Fungus of Pacific Yew. Science Magazine 260(5105): 214-216 1993.

65.Soliman, S. and M. Raizada. Interactions between Co-Habitating Fungi Elicit Synthesis of Taxol from an Endophytic Fungus in Host Taxus Plants. Front Microbiol 22(4),2013.

66.Zaiyou, J., M. Li, X. Guifang and Z. Xiuren. Isolation of an Endophytic Fungus Producing Baccatin Iii from Taxus Wallichiana Var. Mairei. J Ind Microbiol Biotechnol 40(11): 1297-1302.,2013.

67.Malika, S., R.M. Cusidob, M.H. Mirjalili, E. Moyanod, J. Palazonb, et al., Production of the Anticancer Drug Taxol in Taxus Baccata Suspension Cultures: A Review. Process Biochemistry 46: 23-34,2011. 
BADI H. N. et al. 